
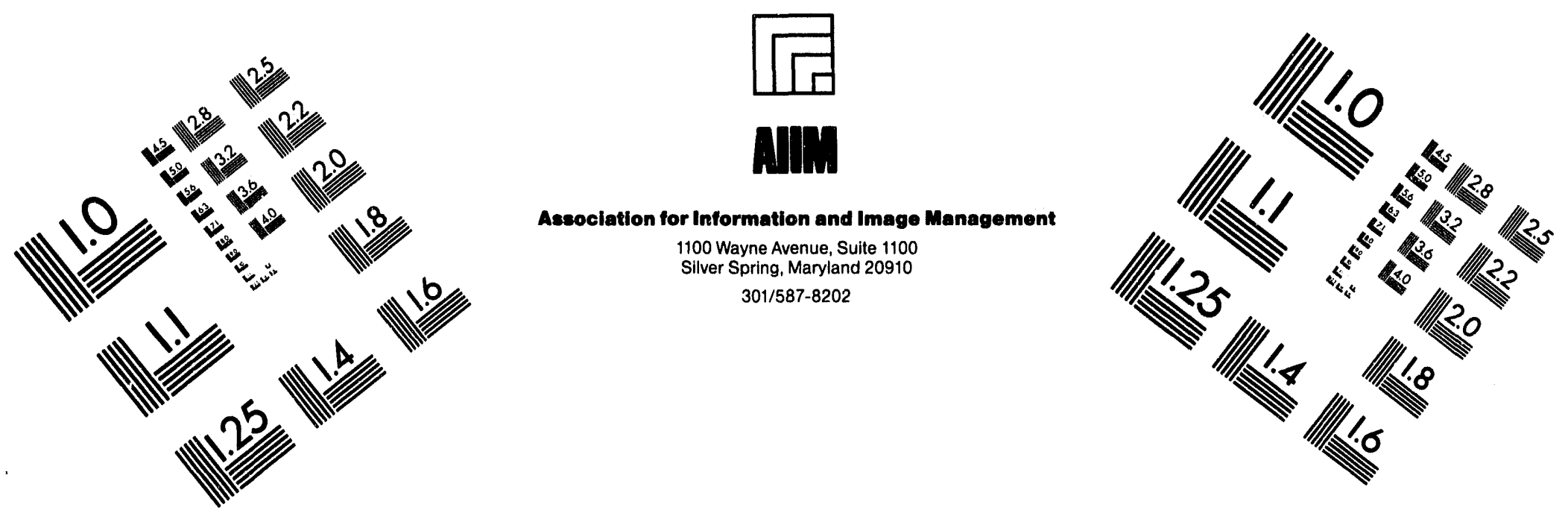

\title{
Centimeter
}

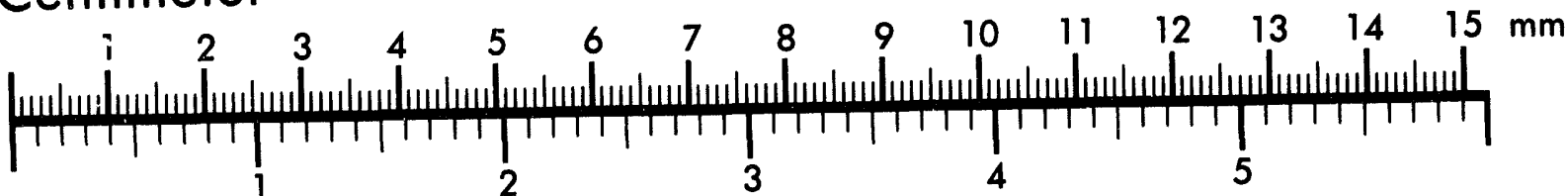

Inches
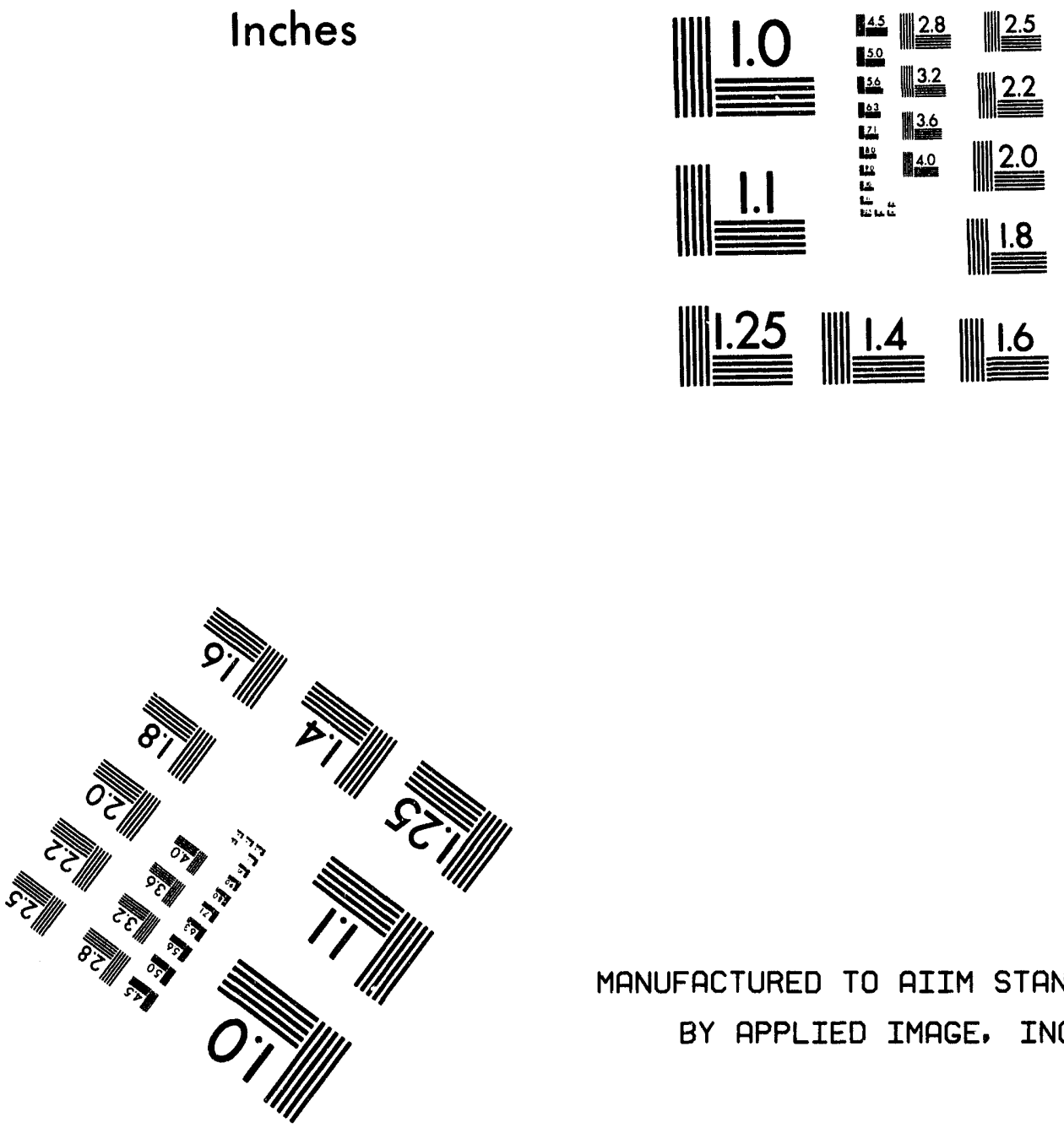

MANUFACTURED TO AIIM STANDARDS

BY APPLIED IMAGE, INC.

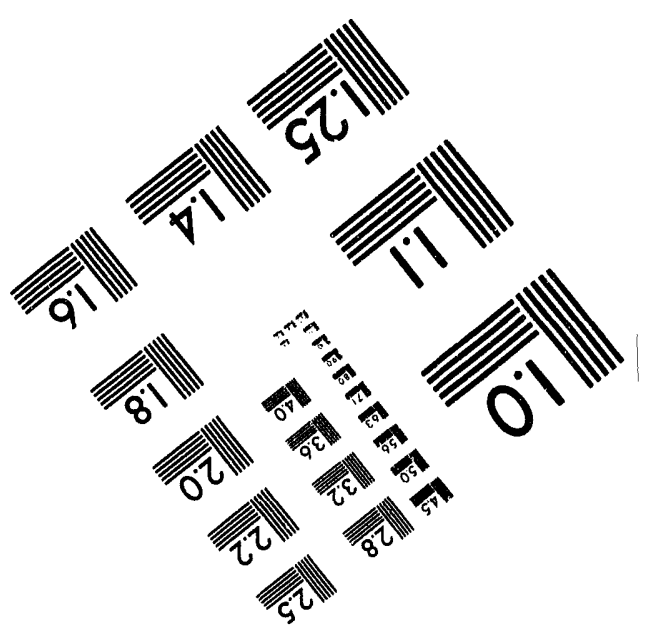



PNL-9784

REC: :

JUN $0>1994$

OSTI

\section{Solid Waste Forecast Database: User's Guide (Version 1.5)}

M. C. Bierschbach

May 1994

Prepared for the U.S. Department of Energy under Contract DE-AC06-76RLO 1830

Pacific Northwest Laboratory

Operated for the U.S. Department of Energy

by Battelle Memorial Institute

Battelle 


\title{
DISCLAIMER
}

This report was prepared as an account of work sponsored by an agency of the United States Government. Neither the United States Government nor any agency thereof, nor Battelle Memorial Institute, nor any of their employees, makes any warranty, expressed or implied, or assumes any legal liability or responsibility for the accuracy, completeness, or usefulness of any information, apparatus, product, or process disclosed, or represents that its use would not infringe privately owned rights. Reference herein to any specific commercial product, process, or service by trade name, trademark, manufacturer, or otherwise does not necessarily constitute or imply its endorsement, recommendation, or favoring by the United States Government or any agency thereof, or Battelle Memorial Institute. The views and opinions of authors expressed herein do not necessarily state or reflect those of the United States Government or any agency thereof.

\author{
PACIFIC NORTHWEST LABORATORY \\ operated by \\ BATTELLE MEMORIAL INSTITUTE \\ for the \\ UNITED STATES DEPARTMENT OF ENERGY \\ under Contract DE-AC06-76RLO 1830
}

Printed in the United States of America

Available to DOE and DOE contractors from the

Office of Scientific and Technical Information, P.O. Box 62, Oak Ridge, TN 37831;

prices available from (615) 576-8401. FTS 626-8401.

Available to the public from the National Technical Information Service,
U.S. Department of Commerce, 5285 Port Royal Rd., Springfield, VA 22161. 
PNL-9784

UC-721

SOLID WASTE FORECAST DATABASE:

USER'S GUIDE (VERSION 1.5)

M. C. Bierschbach

May 1994

Prepared for

the U.S. Department of Energy

under Contract DE-AC06-76RLO 1830

Pacific Northwest Laboratory

Richland, Washington 99352 


\section{Executive Summary}

The Solid Waste Forecast Database (SWFD) system is an analytical tool developed by Pacific Northwest Laboratory (PNL) for Westinghouse Hanford Company (WHC) specifically to address Hanford solid waste management issues. This document is one of a set of documents supporting the SWFD system and providing instructions in the use and maintenance of SWFD components. This manual contains instructions for using Version 1.5 of the SWFD, including system requirements and preparation, entering and maintaining data, and performing routine database functions. This document supports only those operations that are specific to SWFD menus and functions and does not provide instruction in the use of Paradox, ${ }^{(a)}$ the database management system in which the SWFD is established.

(a) Paradox is a registered trademark of Borland International. 


\section{Contents}

Executive Summary $\ldots \ldots \ldots \ldots \ldots \ldots \ldots \ldots \ldots \ldots \ldots \ldots \ldots$

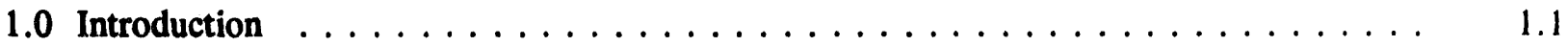

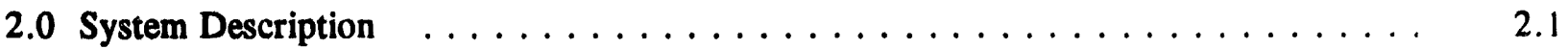

2.1 The System Being Modeled $\ldots \ldots \ldots \ldots \ldots \ldots \ldots \ldots \ldots \ldots \ldots$

2.2 The Solid Waste Forecast Database System $\ldots \ldots \ldots \ldots \ldots \ldots \ldots$

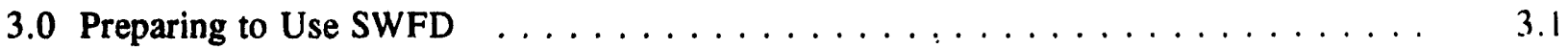

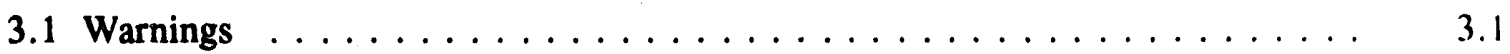

3.2 Installation $\ldots \ldots \ldots \ldots \ldots \ldots \ldots \ldots \ldots \ldots \ldots \ldots \ldots \ldots \ldots \ldots \ldots \ldots .2$

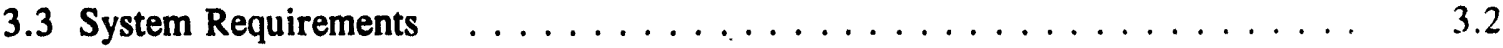

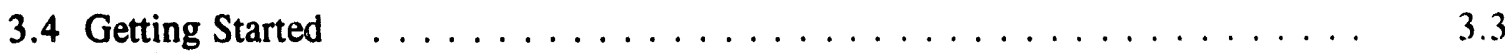

4.0 Entering and Maintaining Forecast Data $\ldots \ldots \ldots \ldots \ldots \ldots \ldots$

4.1 Entering and Editing Forecasts $\ldots \ldots \ldots \ldots \ldots \ldots \ldots \ldots \ldots \ldots$

4.2 Using the Notepad Function $\ldots \ldots \ldots \ldots \ldots \ldots \ldots \ldots \ldots$

4.3 Checking Forecast Data $\ldots \ldots \ldots \ldots \ldots \ldots \ldots \ldots \ldots$

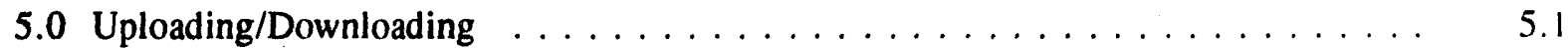

5.1 Uploading Data to the Network $\ldots \ldots \ldots \ldots \ldots \ldots \ldots \ldots$

5.2 Downloading Data and Software from the Network $\ldots \ldots \ldots \ldots . \ldots$

6.0 Maintaining Codes (Lookup) Intormation $\ldots \ldots \ldots \ldots \ldots \ldots \ldots$

6.1 Selecting a Codes Table for Maintenance $\ldots \ldots \ldots \ldots \ldots \ldots . \ldots \ldots$

6.2 Performing Codes Table Maintenance - General Instructions $\ldots \ldots \ldots \ldots \ldots . . \ldots$ 
6.3 Performing Codes Table Maintenance - Waste Generator Table Instructions . . . 6.3

6.4 Maintaining the Model Variable Dictionary $\ldots \ldots \ldots \ldots \ldots . \ldots \ldots$

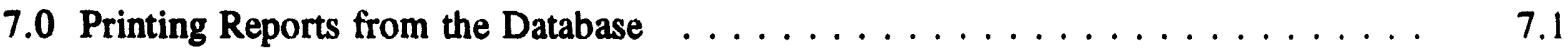

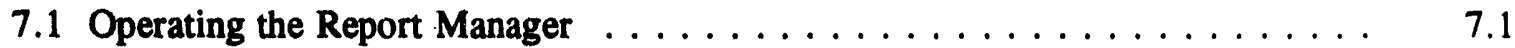

7.2 Report Manager Output $\ldots \ldots \ldots \ldots \ldots \ldots \ldots \ldots \ldots \ldots \ldots$

7.3 Other Ways to Print Existing Reports $\ldots \ldots \ldots \ldots \ldots \ldots \ldots$

Appendix - Versions of the Solid Waste Forecast Databases $\ldots \ldots \ldots \ldots \ldots$ A.I 


\section{Figures}

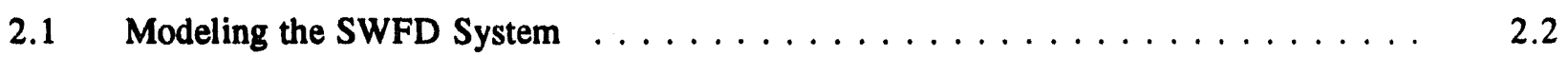

2.2 The Solid Waste Forecast Database System $\ldots \ldots \ldots \ldots \ldots \ldots$

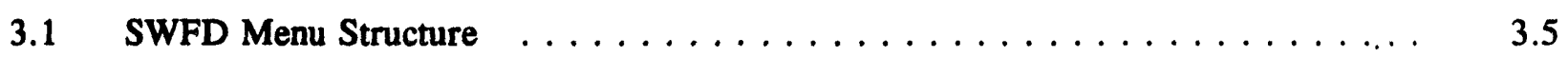

4.1 Typical General Purpose Notepad Screen $\ldots \ldots \ldots \ldots \ldots \ldots \ldots$

7.1 Report Manager - Report Selection Screen $\ldots \ldots \ldots \ldots \ldots \ldots$

7.2 Report Manager - Report Information Menu Screen $\ldots \ldots \ldots \ldots \ldots$

\section{Tables}

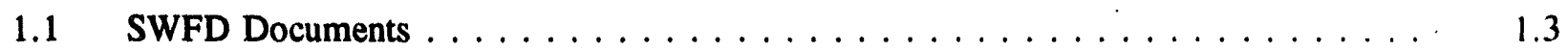

3.1 Paradox Function Keys Used in Operating SWFD $\ldots \ldots \ldots \ldots \ldots \ldots \ldots$

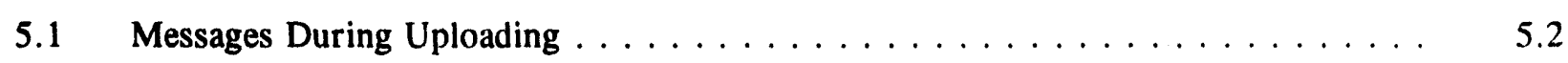

$5.2 \quad$ Messages During Downloading $\ldots \ldots \ldots \ldots \ldots \ldots \ldots$ 


\subsection{Introduction}

Waste management is becoming an ever more important topic. Management of current and future solid wastes will require the development of appropriate treatment, storage, and disposal (TSD) (a) facilities and operations to match the characteristics of the wastes. Inadequate provision of these TSD facilities and operations will surely incur costs in the form of agency fines or excessive handling fees, and may even result in the need to curtail operations. On the other hand, overdevelopment could needlessly commit productive resources and precious capital.

The Solid Waste Forecast Database (SWFD) system is an analysis tool developed by Pacific Northwest Laboratory (PNL) ${ }^{(b)}$ for Westinghouse Hanford Company (WHC) specifically to address these issues at the Hanford Central Waste Complex (HCWC). SWFD provides the ability to:

- develop detailed projections of the volumes of wastes to be managed and the characteristics of these wastes

- characterize and evaluate the impact of alternative TSD technologies or operating strategies on facilities and operations

- assess the impact upon TSD cost and capacity requirements when waste volumes or waste characteristics vary.

This manual describes how to use the SWFD system, Version 1.5, which has been specifically designed and structured to support analyses of WHC's developing solid waste management technology. The manual reflects database development completed through Fiscal Year 1993.

This database has been implemented by PNL using the Paradox database management system, a standard commercial software package produced by Borland International. While the database management software is off-the-shelf, the database design and application software are specific to the SWFD application. This includes data table structures, data entry screens, menus, report formats, and the custom software that ties all these components together into a system. The database application also includes technical documentation and written procedures covering its use and administration.

(a) The terms "treatment," "storage," and "disposal," as used here, do not necessarily correspond to the same terms used under the Resource Conservation and Recovery Act (RCRA). For example, storage, as defined by the model, could correspond to normal process holdup under RCRA.

(b) Pacific Northwest Laboratory is operated for the U.S. Department of Energy by Battelle Memorial Institute under Contract DE-AC06-76RLO 1830. 
The database application has been designed to support the following WHC-managed activities:

- Data entry of forecast information supplied by waste generator organizations: This information is received on standardized forms, reviewed by a data analyst, and entered into the database using a series of on-screen forms. The forecast information covers the years 1994 through 2023 . Data integrity checks are applied before releasing the data into the database.

- Maintenance of existing forecast information: Updated or additional information is entered into the database in a process very similar to the original data entry.

- Notepad maintenance: During preparation and entry of forecast data, it is often necessary to record assumptions made, shortcomings in the data submissions, and other issues that require consideration or action. The notepad function provides a convenient means to record such information during any data entry or maintenance operation.

- Reporting of information: A set of reports addressing the needs of various audiences is provided. Report preparation and production are controlled through the Report Manager feature of the application.

The database application also supports these PNL-managed activities:

- Entry and maintenance of treatment, storage and disposal (TSD) data: This section of the database describes what is done to the forecasted waste streams that enter a proposed treatment system.

- Interface to the model: A set of files, known as a Reference Data Library (RDL), is extracted from the forecast and TSD portions of the database. These files are used by the model to analyze various waste management system scenarios.

This user's guide first describes the SWFD system and explains the data needed to run the model (Chapter 2). Instructions for operating the Version 1.5 SWFD system follow the system description and cover the following activities:

- preparing to use the database, including computer system requirements (Chapter 3)

- entering and maintaining data (Chapter 4)

- using standard SWFD functions, including uploading and downloading (Chapter 5), maintaining the database (Chapter 6), and printing reports (Chapter 7).

This document is part of an integrated set of SWFD system documentation. Five additional documents provide overview information about the SWFD system and detailed instructions in the use. 
maintenance, and application of the other components of the SWFD system. These documents are listed in Table 1.1.

\section{Table 1.1. SWFD Documents}

Title

Syster. Overview

Database Technical Reference Manual

Model User's Guide

Model Technical Reference Manual

Configuration Management and Administrative Plan
Deacriotion

Overview of the SWFD system and potential applications

Development and maintenance reference manual for database software and utilities

User's instructions for model operation and execution

Development and maintenance reference manual for model software and applications

Instruction for long-term system adrrinistration maintenance and configuration management
Primury Audience

Study Managers

Database Specialist

Anulyst

Soltware Enginecr

System Administrator 


\subsection{System Description}

This chapter provides the user with a basic understanding of the solid waste management system being modeled, its representation in the SWFD system, the configuration of the individual SWFD system components, and the data required to support the model.

\subsection{The System Being Modeled}

A generic representation of the solid waste management system modeled by SWFD is shown in Figure 2.1. Solid wastes of a given type or class are received from a number of waste generators and are distributed to various operations. Operations are defined as either treatments or disposals and are linked to other operations to represent a given waste management scheme. At each treatment operation, wastes are shanged in volume or characteristics or both. The waste volumes are then redistrihuted to subsequent operations until a final disposal operation is reached. Because all operations have fixed capacity constraints, each operation has an associated storage option to track any waste distributed to the operation in excess of that capacity.

A distinct series of waste treatment operations are defined for each type or class of waste being accepted and processed. If wastes are converted from one type or class to another as a result of an operation, they are then transferred to the appropriate series of operations for the new type or class. This transfer occurs when wastes leaving each operation are distributed to the next operation in the series.

The various types of data required to support operation of the projection model are shown schematically in Figure 2.1. These data are supplied by two sources:

- Solid waste forecast data come from information on forms provided annually by the facilities generating solid wastes and from inventory data for stored Hanford wastes. These data are supplied to the model as waste generator forecast volumes and characteristics. In Figure 2.1, this source is depicted as an inflow of information from a typical waste generator.

- The information utilized to represent the treatment, storage, and disposal operations is based on historical information obtained from the Solid Waste Information and Tracking System (SWITS) database, ${ }^{(a)}$ waste generator forecast information, and current design information for the Hanford Solid Waste Programs system.

(a) Maintained by WHC; not part of the SWFD system developed by PNL. 


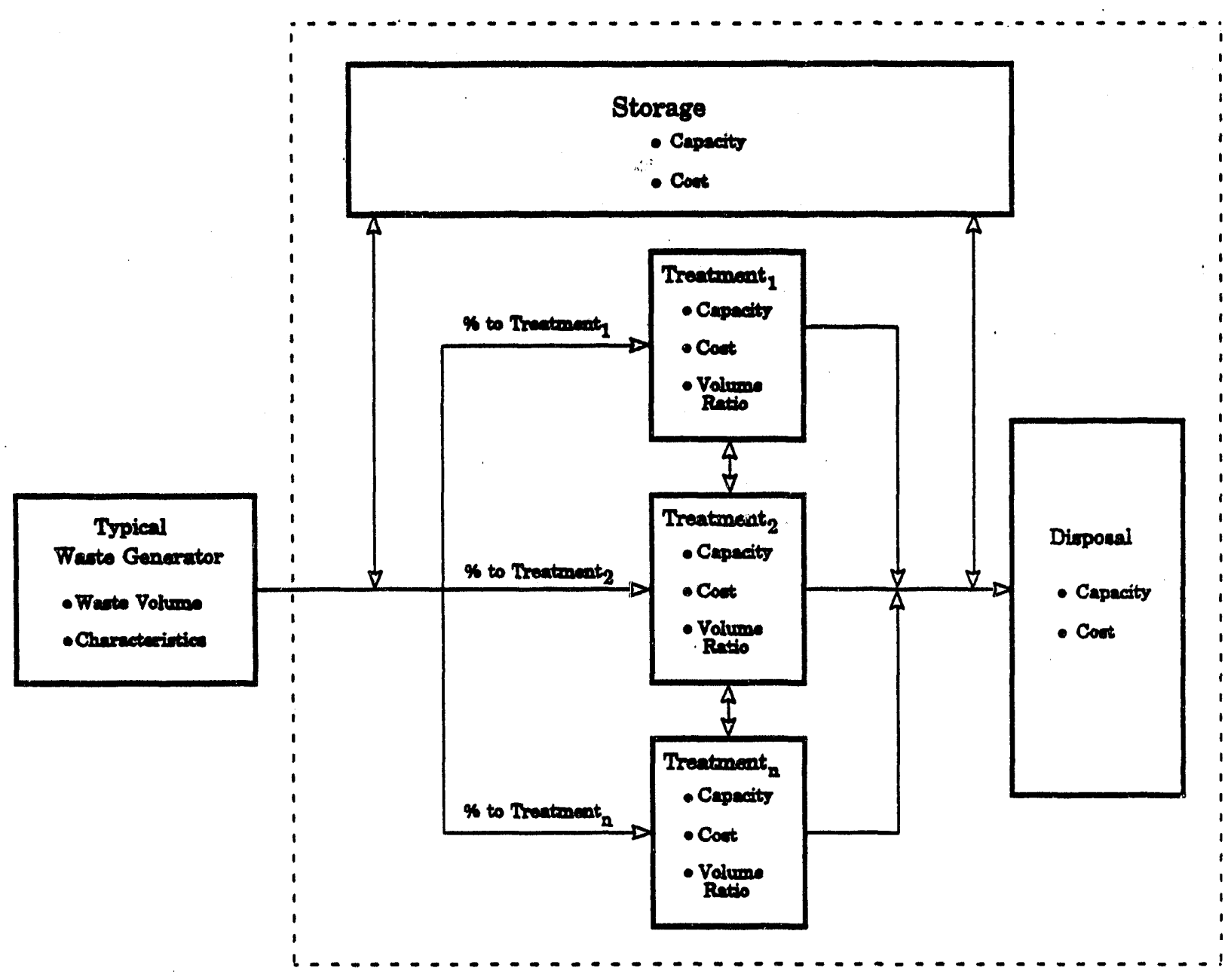

Figure 2.1. Modeling the SWFD System

Distribution of incoming waste receipts and of wastes leaving each treatment operation is handled by the flow percentages shown in Figure 2.1. These percentages are used to allocate incoming waste volumes to initial operations and to distribute wastes from one operation to the next operation(s). The percentages are based upon waste properties (physical, chemical, radiological, etc.) that define "treatability" and the operating strategy defined for an analysis case. 


\subsection{The Solid Waste Forecast Database (SWFD) System}

The SWFD system, shown in Figure 2.2, uses a data-driven logistics model to provide detailed analyses of the generic system described above. The SWFD is supported by a database that is used to store and maintain forecasts of waste volume and characteristics, as well as the characteristics of the TSD operations and facilities.

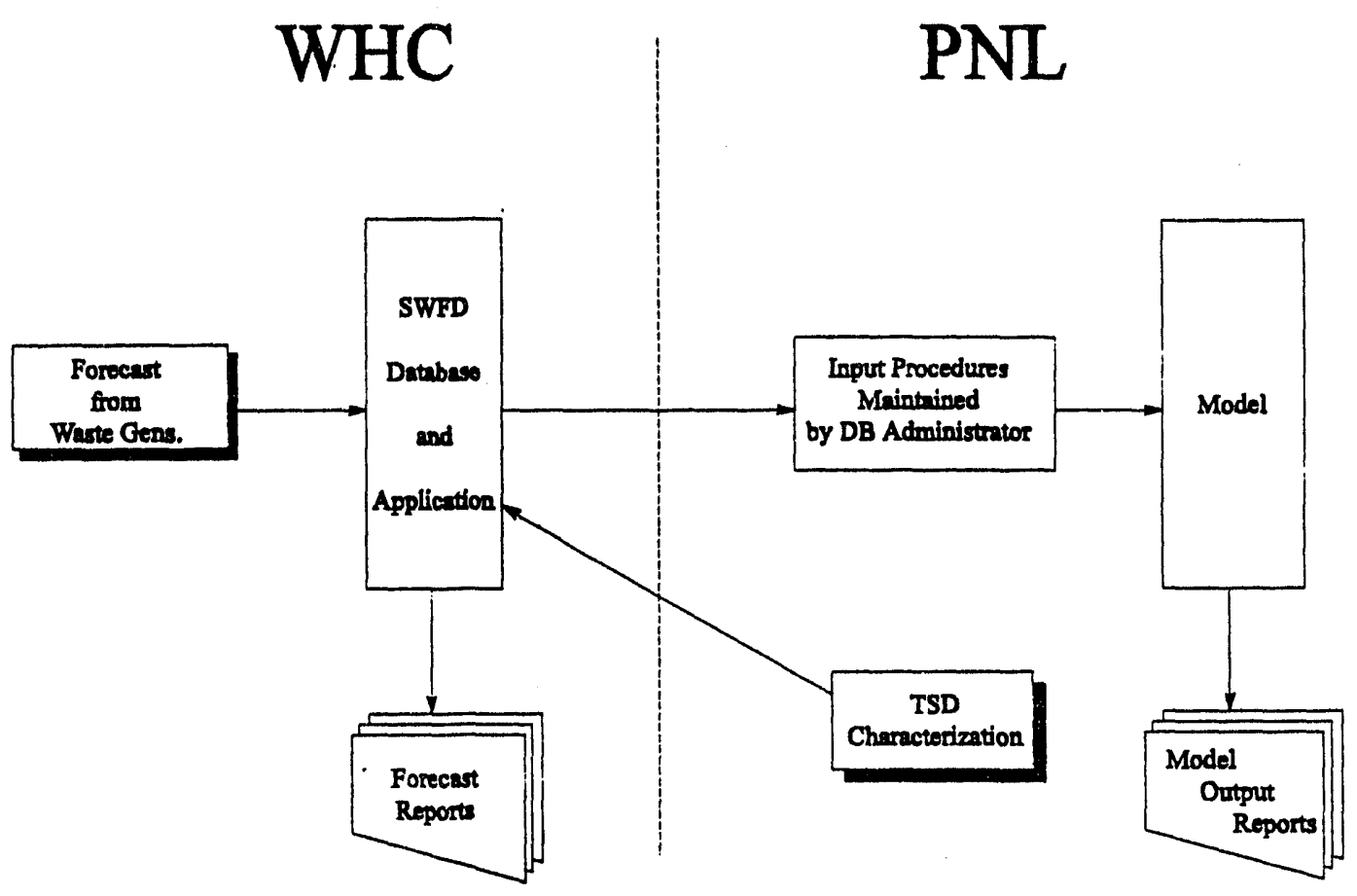

Figure 2.2. The Solid Waste Forecast Database System

The SWFD database operates using the Paradox database management system. Forecast information is entered into the database by WHC staff through custom data entry screens. These screens are similar in layout to the paper forms submitted by the waste generator organizations. TSD data are entered from process flow sheets created by PNL according to WHC specifications. The other PNLoperated components of the system are external to the database and covered in other SWFD system documentation.

In previous years, TSD information was passed from the database into a set of specially formatted electronic files called the Reference Data Library (RDL). The RDL was then accessed through a graphical user interface that guided the user through the selection of case-specific data sets. This year, the model requirements have changed so that the RDL is no longer required. In place of the RDL files and its graphical interface, the database administrator maintains specially prepared forecast files meeting the specifications of the SIMSCRIPT model. To create input files for the SIMSCRIPT model, 
the database administrator runs two scripts from within the Paradox environment. The first script joins together the model forecast files in the required manner to create a single input file. The second script processes this file and creates a file that can be read in directly by the SIMSCRIPT model. Because each model run is unique, the scripts must be modified for each run. 


\subsection{Preparing to Use SWFD}

This chapter explains how to access the SWFD application and prepare to perform routine operations in the database. Section 3.1 provides some general warnings for the user, and Sections 3.2 and 3.3 discuss installation and technical requirements. The last part of this chapter, Section 3.4, includes instructions on the actual execution of the database application. Table 3.1 lists most of the common ways in which function keys are used in database operations.

Table 3.1. Paradox Function Keys Used in Operating SWFD

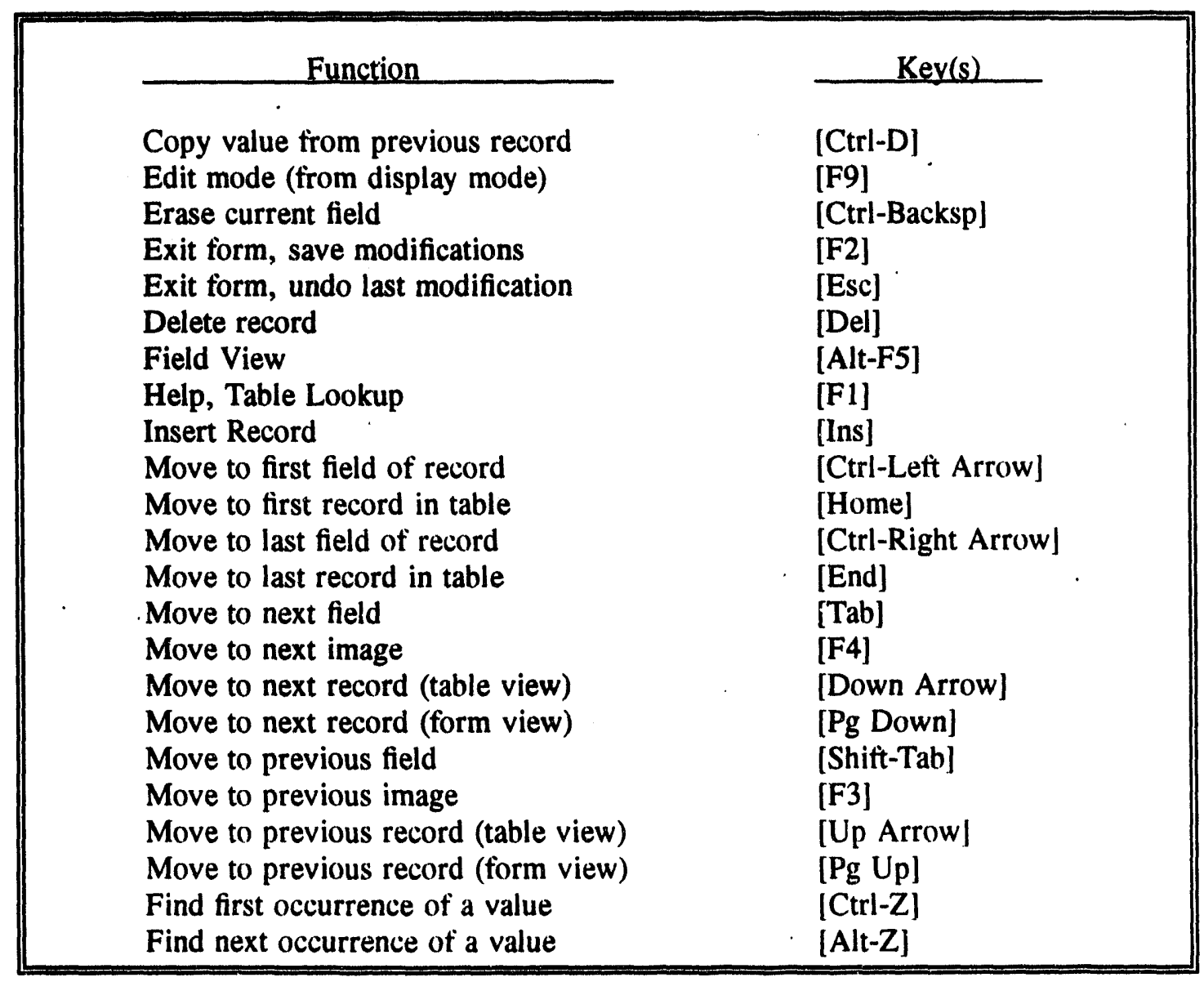

\subsection{Warnings}

Because of the complex relationships among the types of data stored in the database, keep in mind the following warnings: 
- The SWFD application does not accept forecast information unless the waste generator facility to which the forecast applies has been defined in the database. A waste generator record is created in the system by entering it into the waste generator table, a master list of waste generators. This table defines the waste generator organization to the system and provides some descriptive information.

- Before attempting to enter data, review and organize all information and tag it with waste generator abbreviated names. Once data have been entered, changes to certain key data elements, such as waste generator names, waste categories, and waste classes, can cause inconsistencies and errors in the database. Careful organization and planning and an initial review of the data supplied by the waste generators are very useful in minimizing later problems with the database.

- All data entry and maintenance should be performed using menu selections. Entering data directly into the underiying Paradox tables will bypass many of the data integrity checks that are useful in catching errors and inconsistencies.

\subsection{Installation}

Installation of Version 1.5 of SWFD should be done under guidance of the database administrator. Requirements for directory structure, hard disk space, Paradox installation defaults, and other issues are discussed in the Database Technical Reference Manual.

\subsection{System Requirements}

To provide full operation of the SWFD system, the following system hardware requirements must be satisfied:

- IBM PC, XT, AT, PS/2 or compatible computer

- 640 kilobytes of RAM

- Connection to the PNL network, as described in the Database Technical Reference Manual.

- 10-20 megabytes of free work space on a local or network hard disk.

- Hewlett Packard Laserjet II or later printer. 
The following are recommended for performance, but not required:

- 80386 or later processor.

- 2 megabytes or more of expanded memory, or a similar amount of extended memory converted to expanded memory using memory management software.

Operation of SWFD requires the following software:

- DOS Version 3.3 or later.

- Paradox Version 3.5 (stand-alone or accessible from the network) - See the database administrator for information about Paradox setup defaults and network access. No other version of Paradox should be used.

- Network configuration defined to include connections to appropriate servers, as described in the Database Technical Reference Manual.

The SWFD application has been sucessfully tested as a task running under Windows 3.1. Running Paradox as a Windows task does result in slower performance, however. With some memory configurations, Paradox may not get all the memory from Windows that it needs to support the SWFD application. Paradox software does not execute reliably under OS $/ 2$ Version 1.x but appears to perform adequately in OS/2 Version 2.0. A 386 or 486 processor with at least 8 megabytes of memory is mandatory for running Paradox under Windows or OS $/ 2$.

\subsection{Getting Started}

Paradox menu selections are shown in bold in the following steps.

- If necessary, boot DOS or OS/2 2.0 on your computer and then execute Paradox.

- Establish the directory containing SWFD files as your working directory. Select TOOLS, MORE, DIRECTORY from successive Paradox menus and then enter "J:ISWPMDB93" when asked for a directory name. This directory may also be set as the detault by customizing your Paradox installation or by including it in a Paradox initialization script. See the database administrator for assistance.

- Execute the SWFD startup script. Select SCRIPTS, PLAY from the menus and then enter the script name as "SWPM." 
- Choose 2) FY93 (v1.5) from the SWFD database selection menu. After entering the correct password, the SWFD application main menu appears. Note that the software uses the older acronym SWPM (Solid Waste Projection Model), instead of SWFD. See Figure 3.1 for a diagram of the application menu structure. This diagram shows the main menu options on the left and successively lower-level menus to the right. The lowest-level menu options execute the database operations shown next to them in the diagram.

Note: Other versions of SWFD operate differently. Specific instructions given in this manual may not be valid for versions other than Version 1.5. See the Appendix for a list of SWF databases and descriptions of each. Earlier versions of SWFD were called Solid Waste Projection Models (SWPM). 


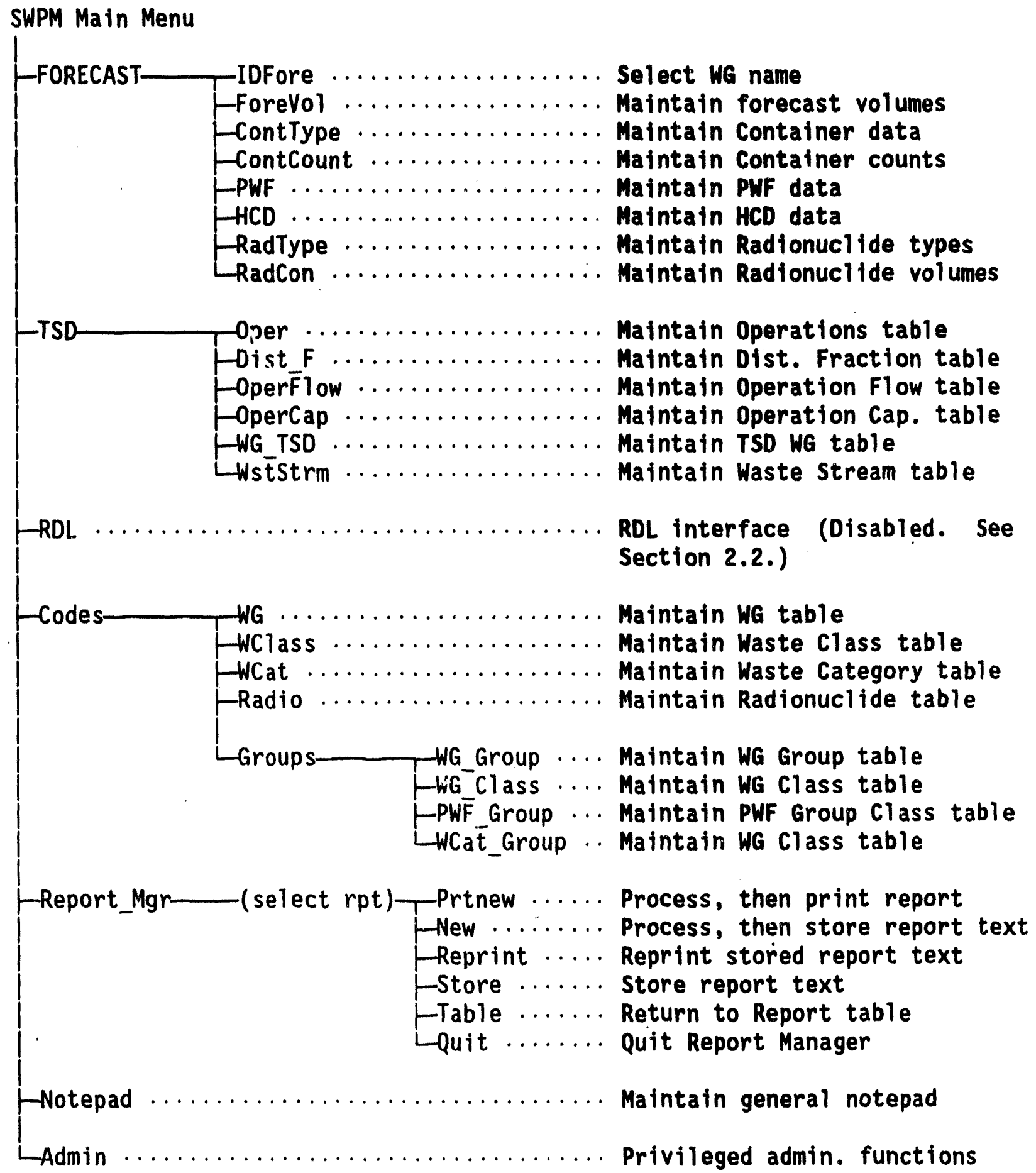

Figure 3.1. SWFD Menu Structure 


\subsection{Entering and Maintaining Forecast Data}

This chapter describes the process of entering the annual waste generator forecasts into SWFD. These forecasts are provided by the waste generator organizations on data collection forms sent to them each year by WHC. The procedures below are a guide to entering new data or modifying existing data in the database.

Forecast information is entered into SWFD through several screens that generally correspond to the structure of the data collection forms. These screens are defined by Paradox data entry forms or by direct views of one or more of the SWFD tables. Access to the screens is accomplished by choosing Forecast from the SWFD application Main Menu. This selection leads to another menu from which other options are chosen, as explained in the detailed procedure in the following sections.

\subsection{Entering and Editing Forecasts}

Waste generator forecasts are entered into six tables, each of which has its own menu selection. Forecast entry or update is accomplished using the following steps:

- Select Forecast from the main SWFD menu.

- Choose IDFore from the next menu. Select a waste generator by highlighting it with the cursor, then pressing [F8] or [Esc]. All data entry activity following this selection applies to the waste generator selected, until another selection is chosen. If a waste generator has been selected, it will appear on the Forecast menu screens.

- All of the remaining choices on the Forecast menu involve entering or updating data in one of the six tables that hold forecast data. The data entry selections reflect the names of the database tables in which each type of data is stored:

Table Type of Data To Enter

ForeVol Volumes in cubic feet by waste class.

Conttype Non-standard containers as specified by the WG.

Contcount Annual container counts by waste class.

PWF Physical waste form percentages for each waste class and container type.

HCD Hazardous content descriptor percentages for each mixed or hazardous waste class and PWF type. 
Radtype Radionuclide types (fission product beta/gamma, uranium, Pu-238/239, or volitile radionuclide) by waste class, container and PWF.

Rad Radionuclide volumes and concentrations by waste class.

- If a new forecast is to be entered, select each of these options in the order shown above and complete the data entry before going to the next item on the list. The HCD selection is used only if the current waste generator's forecast includes mixed or hazardous waste.

- A table will appear containing the data for the selected menu option. The order of selections on the Forecast menu should be used as a general guide to the order of data entry, since the validity of data entered may depend on the contents of another table. For instance, container count (ContCount table) information can only be entered for waste classes and container types that have volumes entered in the ForeVol and Conttype tables. After container and container count data are entered, PWF information can be entered. Finally, once PWF data are entered, the HCD data may be entered. Data for the Radtype table may be entered after PWF data are entered. Data for the last table (Radcon) may be entered at any time, after volumes have been entered into the Forevol table.

Note: When data are incomplete or inconsistent, or issues are raised by the nature of the data, make notes about the situation using the notepad function. See Section 4.2 for instructions.

- Press [F2] to finish and save your work. If you decide not to save the data, press [Esc].

\section{Interruptions in Data Entry}

- Work can be interrupted before completing data entry for a waste generator in every table. However, updates should be finished within any one of the tables.

- In some cases, you will not be allowed to save partial entries, and you must either finish the work or press [Esc] and lose what work you did get done. For example, when entering PWF data, the decimal fractions entered must total to 1 for every waste class with non-zero volumes, or none of the data on that screen can be saved.

- Take note of where work was interrupted because you are not automatically returned to a previous stopping point in the next session.

- Keep in mind that incomplete data entry for a waste generator may cause inconsistent totals on reports, should any be run before the work is finished. 


\section{Data Integrity Checks}

- In most instances where names for waste generators, waste classes, container types, PWFs, HCDs or other descriptive labels are needed, a list of valid choices is presented. These choices may appear as predefined items on the screen or in a popup table from which an item may be selected. Additionally, some data entry screens allow entry to an "Other" category. Use the notepad to record explanations of "Other" usage or to capture information on other issues that arise.

- Some numeric entries are checked. As noted above, distribution factors such as PWF, HCD, and container percentages must be entered as decimal fractions summing to 1 . You will not be able to exit from a data entry process until the necessary corrections are made unless you press [Esc] and discard the data you entered on the current screen. Volume data (entered as cubic feet) are not checked, since there is no basis for automatically validating volumes.

\subsection{Using the Notepad Function}

The notepad provides a means to record notes, when some explanation is necessary. Notes can be made at any time during data entry. In special situations, when the forecast specifies an "Other" type of characteristic or when a nonstandard box-type container is specified, the notepad should be used.

To bring up the notepad during data entry, press [Ctrl-N]. Enter up to 160 characters of notes and press [Enter] to return to the data entry screen. See Figure 4.1 for an example of the notepad screen.

These are examples of circumstances in which a note should be made to the notepad:

- Some aspect of a waste generator forecast is unclear or inconsistent, but the forecast is generally complete enough to enter. An example of this would be when a waste generator fails to include radionuclide information but has submitted an otherwise complete forecast. In such a case, a note would be made as a reminder that the waste generator's listed contact person must be called with a request for the missing information.

- A significant change to data is made and the reasons for the change need to be recorded. For example, if a forecast was removed from the database because it duplicated a submission from another organization, an explanatory note should be entered.

- An assumption is needed to complete entry of a forecast before reporting deadlines. It might be necessary, for instance, to define the container used by a waste generator as "55G DRUM" because no container type was specified. A notepad entry would be required that draws attention to this assumption and describes intended remedial action. Failure to define any container type at all would have otherwise resulted in inconsistent content among certain SWFD reports. 


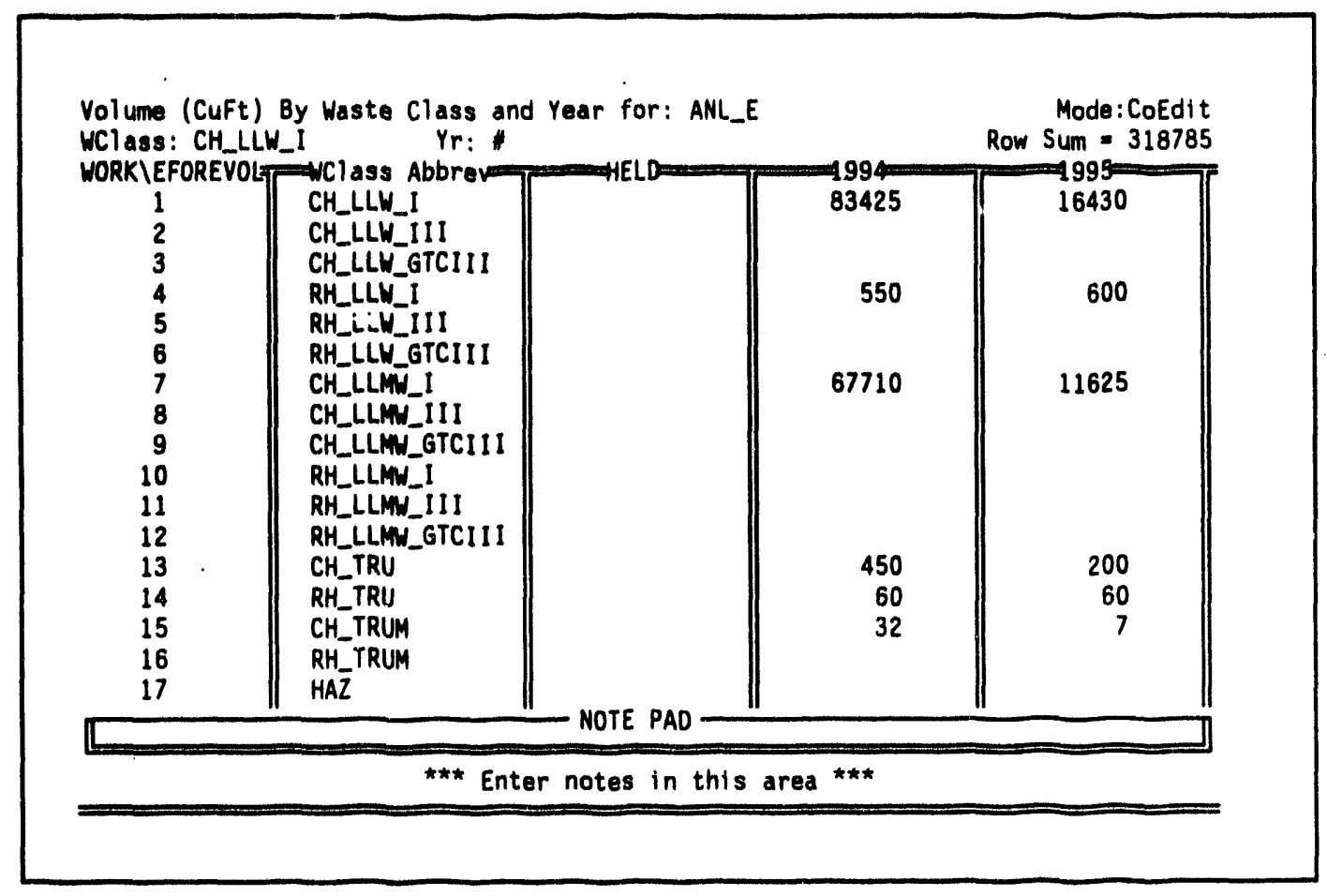

Figure 4.1. Typical Notepad Screen

- If the data entry operator intentionally enters data differently than it appears on the waste generator forecast form, one or more notes should be entered to explain and justify the differences.

- At any other time when an explanation would be helpful or an issue needs to be raised.

Important Points About Using the Notepad

- Notes are stored in separate tables and are printed using a report selections in the Report Manager. When notes address issues that need to be resolved, they remain on the report until a resolution is recorded by the database administrator and the entry is removed.

- Previously entered notes cannot be recalled for editing during data entry. They can be viewed and edited by selecting Notes from the main SWFD menu.

- Due to memory constraints, only 10 notes of each type may be entered during a single data entry process. A warning appears if you attempt to exceed the limit. If more notes are needed, end the data entry . process as usual. This causes temporarily stored notes to be written to notepad tables and makes room for a new batch. Resume data entry by reselecting the same Forecast menu option as before. 
- Take care to position the cursor at the specific location on the screen to which the note applies.

- When notes are made in the notepad, the following items are also recorded automatically:

- current table name

- current field name

- current field content

- today's date

- user ID

\subsection{Checking Forecast Data}

In order to fully verify information entered into the SWFD system, you will need to inspect the data visually. Internal consistency checking is performed during data entry for some values, but other data cannot be tested automatically. Items needing review include the completeness and accuracy of the waste generator table, the volume amounts and radionuclides of forecasted wastes, and the specific selections of PWFs, containers, and HCDs for each forecast waste class.

For visual inspection, view the data using the data entry/editing processes described in Chapter 4 or generate reports from the Report Manager as explained in Chapter 7. 


\subsection{Uploading/Downloading}

The network copy of the database is intended to be the reference version of the database and is subject to a number of quality assurance (QA) requirements. These requirements include password protection and strict change control. You are encouraged to make and use local copies of the database in certain situations where "what-if" changes are made, or when slow network performance becomes a major hindrance. Using a local copy for data entry yields a number of benefits. You can avoid the sometimes sluggish system response caused by the combination of network traffic and processing overhead from Paradox data entry software. Software maintenance, ad hoc queries, and operation of the model interface on the network reference database will not interrupt or impede local data entry. For these reasons, productivity is usually greater when accessing a local copy compared with using the network database. Also, it is possible to divide the data entry workload among multiple users, and this activity goes more quickly on local copies of the database.

The database administrator must coordinate transfers of data from one or more local databases to the network database. This process needs special attention and coordination if more than one local database is involved. Be sure to discuss any intended use of upload and download procedures with the administrator prior to their use. The user or users responsible for entering and maintaining forecast data should upload data to the network regularly to keep the reference database current and to guard against loss of data. The steps required to upload data are detailed in Section 5.1. The download process, explained in Section 5.2, provides the means to create local copies of the current versions of software and data.

\subsection{Uploading Data to the Network}

- When a significant amount of new data is entered, it is your responsibility to notify the database administrator that an upload is needed. The administrator may also request an upload to ensure that the latest data are available for reporting or modeling purposes.

- In contrast to the previous version of the database, uploading is performed in DOS for this version, rather than as a Paradox operation. If the SWFD application is running, end it and then terminate Paradox.

- Verify that the default drive is the local disk containing SWFD data and that the current directory is ISWPMDB93. 
- Execute the upload process by entering the command UPLOAD. You must confirm your intention to upload by pressing [Enter]. Otherwise, terminate the process by pressing $[\mathrm{Ctr}]-\mathrm{C}]$.

A check is made to ensure that the network upload area is ready to receive the data. If the area has not been prepared, the upload process will terminate with an appropriate error message. Advise the database administrator of the problem immediately.

The messages that may be generated during uploading are listed in Table 5.1.

Table 5.1 Messages During Uploading

\begin{tabular}{|l||}
\hline Normal Messages \\
Checking current drive and directory... \\
The default drive and directory are checked. The user must not be in the SWPM \\
network directory. \\
Checking for availability of the upload directory... \\
The existence of the upload directory on drive J is confirmed. This also ensures that \\
the required network connection exists. \\
Checking that upload area is empty... \\
The readiness of the upload area is verified by checking for several files. If these \\
files exist, they may represent a previous upload that has not yet been processed. \\
Data upload will be performed to drive J. \\
Ready to proceed? (Y/N) \\
The user must confirm before the upload operation is executed. \\
Data upload complete. \\
The upload has finished successfully. \\
Logging event now... \\
Upload process completed normally. Advise DB Administrator. \\
The logging of the upload has taken place.
\end{tabular}


Table 5.1 Messages During Uploading (contd)

\section{Error Messages}

Sorry, you must upload from ISWPMDB93 on your local drive.

You attempted to upload from the wrong directory or from the network database. Set the default drive and directory to the location of the local copy of the SWPM database and retry.

Sorry, the upload area was not found. Make sure you have a network connection for $J$ drive and that it is defined for the correct network share. Call the database administrator if you need assistance.

The upload process could not find the network database. The network connection may not exist, or the database may not be available.

Sorry, upload area is not empty. Notify the DB administrator.

There are data files in the network upload directory that should not be overwritten. The database administrator must remove these files first. 


\subsection{Downloading Data and Software from the Network}

Approval from the database administrator is not needed for downloading. The user should be aware, however, that downloads will write over existing files. If a data download is executed in a situation where the local copy is more current than the network, information will be lost. A policy of maintaining current backups of local SWFD data is extra insurance against such an occurrence.

There are two.download processes available: one for data and another for software. A sottware download will include the database application software with its related screens, menus, and system tables but not Paradox itself. The instructions below apply to both data and software downloading.

- Downloading is performed in DOS, not from within the database application. If the SWFD application is running, end it and then terminate Paradox.

- Establish J drive as the default drive and set ISWPMDB93 as the current directory.

- To download data, enter DLDATA < target drive > at the DOS prompt; to download software, enter DLSOFT < target drive >. The < target drive > parameter may be any upper or lower case letter. If this parameter is not specified, $\mathrm{C}$ will be assumed to be the target drive.

Examples:

DLDATA Downloads data with $\mathrm{C}$ drive as the target.

DLSOFT e Downloads sottware to the E drive.

Notes: A directory named ISWPMDB93 must exist on the target drive. Subdirectories will be created as needed, however.

It is possible that some of the above drive choices could be configured as network drives on some workstations, such as on a computer with no hard disks. In such cases, the download process will be successtul, but the performance benefit of using a local drive will not be realized.

- The user must confirm the target drive before the download process will execute.

- If a data download will overwrite existing SWFD data files, confirmation will be requested.

The messages that may be generated during processing are listed in Table 5.2. 
Table 5.2. Messages During Downloading

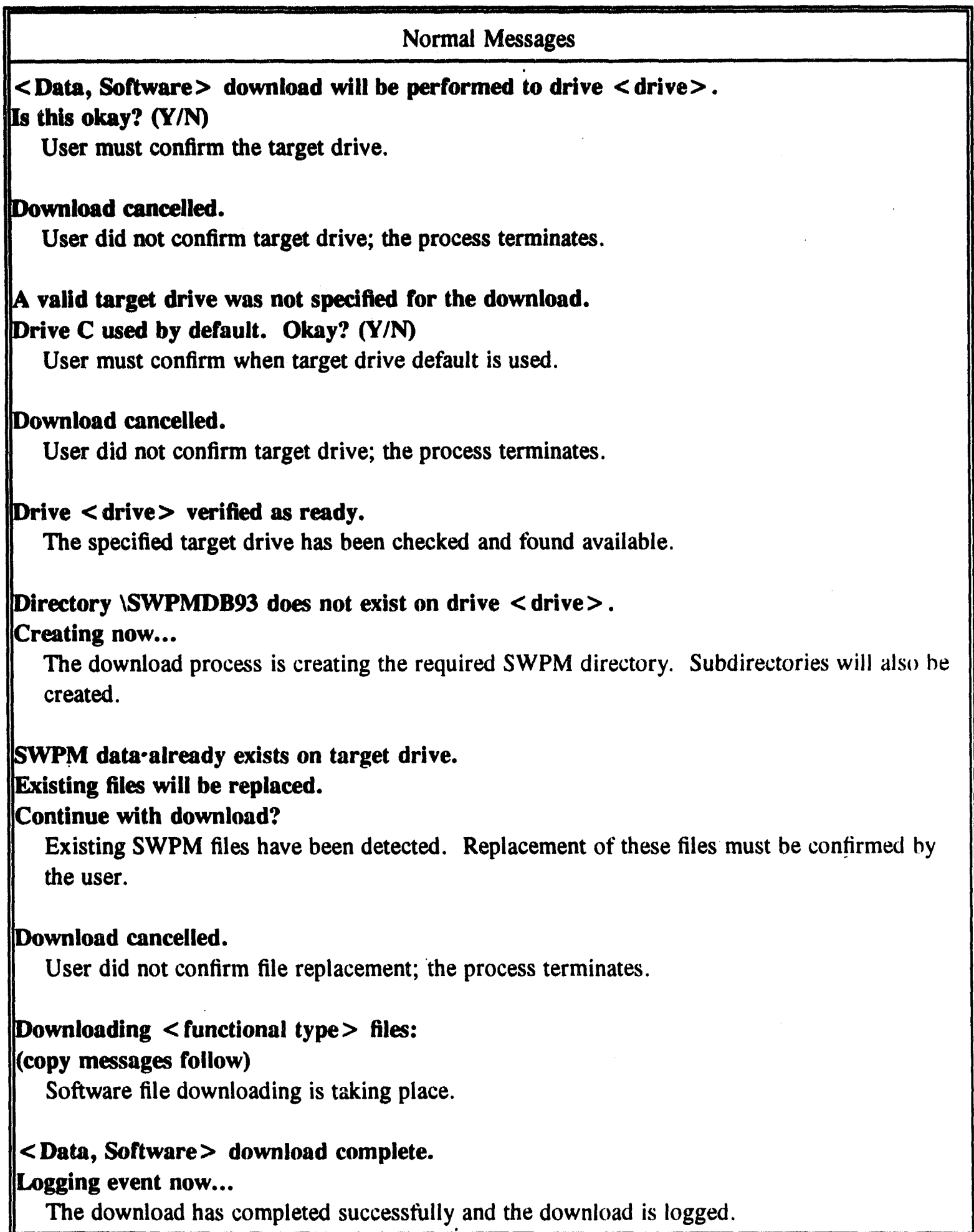


Table 5.2. Messages During Downloading (contd)

\begin{tabular}{|l||}
\hline Error Messages \\
\hline Sorry, drive < drive > is invalid. Try again. \\
The drive specified was A, B, or J, or the drive to be used could not be found. The \\
download process terminates after this error occurs. \\
Sorry, you must download from J:ISWPMDB93. \\
The download was not executed from the network area containing the SWPM database and \\
software. The process will terminate after this error occurs.
\end{tabular}




\subsection{Maintaining Codes (Lookup) Information}

The SWFD contains a number of lookup tables used for the following purposes:

- to validate data, restricting the content of some fields to members of a list

- to support grouping and subtotaling of information on reports

- to control the order in which items are printed or displayed

- to permit the substitution of expanded names on reports in cases where the database contains only abbreviations. Maintenance requirements for most codes-type tables are very modest. Access to these tables is controlled via passwords. Except for defining new waste generators, most codes table maintenance will be performed by the database administrator.

\subsection{Selecting a Codes Table for Maintenance}

- Select Codes from the Main Menu.

- Choose one of the following options:

WG Table of valid waste generator names.

WClass Table of valid waste classes.

WCat Table of valid waste categories.

Radio Table of valid radionuclides.

Groups Tables of various groups.

Submenu of Groups tables

WG_Group Table of waste generator groups

WG_Class Table of waste generator classes

PWF_Group Table of PWF groups

WCAT_Group Table of waste class groups 


\subsection{Performing Codes Table Maintenance - General Instructions}

Except for the waste generator table (option WG), the editing procedures are generally the same for all the tables listed in Section 6.1. Specific instructions for the waste generator table appear in Section 6.3 below. General codes table maintenance instructions are as follows:

- Select Codes from the Main Menu.

- Select the appropriate codes table as directed in Section 6.1. The table containing the selected data appears.

- Use the [Ins] key to add a new item. Enter the new item name in response to the prompt that appears above the table. An error message will appear if the name is already in use. Otherwise, the insert is performed in the appropriate place in the table. Be sure to complete the process by entering data in any other fields that the new item may have. Press [F2] to save the new item.

- If an existing code name is to be changed, place the cursor on the row containing the old name and press [Ctrl-F9]. Alternately, select Update from the menu that appears after pressing [F10].

Note: Do not change the name field directly as you would any other field. [Ctr]-F9] must be used so that the entire database will be updated with the new name.

- Fields other than the name of the code can be updated by pressing [F9], making the changes and then pressing [F2] to save them.

- Delete by pressing [Del]. If the code to be deleted is not in use in the database, the delete will be accepted and performed. Codes that are in use elsewhere in the data will not be removed from a codes table.

- The general purpose notepad may be used while editing codes tables. Press [Ctrl-N] to invoke it.

- To finish codes maintenance, press [F2] to make sure updates are saved. Then, press [F8] to cleal the screen and return to the menu. 


\subsection{Performing Codes Table Maintenance - Waste Generator Table Instructions}

- Select Codes from the Main Menu.

- Select WG from the next menu. The table of existing waste generators appears.

- To insert a new waste generator, press the [Ins] key. A prompt will appear to get the waste generator abbreviation. After verifying that it does not already exist, a row for the new waste generator will be created in the appropriate place in the table. Be sure to complete the other fields for the new entry as well. Waste generator group and class fields are automatically validated and can be selected from lists by pressing [F1]. Finish entering the new item by pressing [F2].

- If an existing waste generator abbreviation is to be changed, place the cursor on the line to be changed and press [Ctrl-F9]. Alternately, select Update from the menu that appears after pressing [F10].

Note: Do not change the waste generator field directly as you would any other field. [Ctr]-F9] must be used so that all occurrences of the old waste generator abbreviation are thanged to the new value in the entire database.

- Fields other than the waste generator abbreviation can be updated by pressing [F9], making the changes, and then pressing [F2] to save them.

- Delete by pressing [Del]. If the waste generator to be deleted is not in use in the database, the delete will be accepted and performed.

- After waste generator table maintenance is complete, press [F2] to make sure updates are saved. Then, press [F8] to clear the screen and return to the menu.

- At any time during the editing process, the general purpose notepad may be invoked by pressing [Ctrl-N]. For more information about the notepad, see Section 4.2.

\subsection{Maintaining the Model Variable Dictionary}

The model variable dictionary (MVD) contains names, descriptions, and other information about variables used in the SWFD. No special procedures were developed to perform maintenance on the 
tables involved, since changes are very rare. In view of the lack of any provision within the SWFD application for performing maintenance on the MVD, all required updates to this area of the database should be left to the database administrator. 


\subsection{Printing Reports from the Database}

Reporting in SWFD is accomplished using the Report Manager selection that appears on the main SWFD menu. The Report Manager is a set of Paradox tables, programs, and text files that work together to present a list of available reports or other processes. An item is selected from this list as if it were a menu. The report process is then executed and status messages are displayed. In some repurt processes, you may be asked for further input. Output takes the form of printed reports, text files cuntaining images of the reports, and, in some cases, spreadsheet flles. A Hewlett Packard Laserjet II or later model printer is assumed for all print output.

Reports can be generated from the Report Manager in two different ways. For most purposes, the preferred method is one which performs the complete process of retrieving, manipulating, and summarizing current data into a result table. The desired output, generally a report or spreadsheet, is then generated from the result table. This method has the advantage of always producing output hased on the current database contents. Report output can also be generated by a faster method in which output comes directly from the existing result table without refreshing it from the database. This method is acceptable only when the user is certain that no changes to data have occurred since the result tahle was created. When additional copies of a report are needed or another related report process has already been run that updates the same result table, this method can avoid some unnecessary processing.

In each of the two methods, you can select whether output goes directly to the printer or is held in a text file that can be viewed, distributed electronically to other users, imported into a word processorr. or printed. When the print option is used, the corresponding text file will automatically he updated su that it contains the same information that was sent to the printer.

\subsection{Operating the Report Manager}

- From the Main Menu, select Report_Mgr. A table of report selections appears. See Figure 7.1 for an example of this screen.

- Move the cursor to the report you want and press [F2] to select it. Otherwise, press $|F 8|$ or $\mid$ Esc| to terminate the Report Manager.

Note: To assist in making the right selection, the report identified as D100 lists all available reports and includes additional information that does not appear on the Report Manager screen. It may be helptil to print this report first.

- After a report is selected, a screen is displayed with more information about the repurt (see Figure 7.2 for an example): 
Place cursor on report to be selected, then press F2.

Press $\mathbf{F 8}$ to exit

\begin{tabular}{|llccc|}
\hline \multicolumn{5}{c|}{ FY-1993 SUPM OATABASE REPORTS } \\
REPORT MANAGER
\end{tabular}

Figure 7.1. Report Manager - Report Selection Screen

PrtNew New Reprint Store Table Quit

Run complete process including new data - store and print

\section{SELECTED REPORT INFORMATION}

Report Name: FY-1993 SWPM OATABASE REPORTS

Report 10: 0100

Processing Time: .3

Last processed: $2 / 10 / 94$

Print file Size: 16384 bytes

Figure 7.2. Report Manager- Report Information and Menu Screen 
- Report name: Similar to the title printed on the report.

- Report ID: A unique code assigned to a report or other process. Report IDs begin with "D." Processes that produce spreadsheets or other forms of data files begin with "X." Many "X"type reports produce printed reports as well. Descriptions included in report D100 identify the nature of the output from each process.

- Processing time: This represents how long this selection took to finish when it was last executed. This time is only a general guideline, since it is highly dependent on the type of computer used, amount of data in the database, optional processing steps that you have selected or rejected, whether the database is a local copy or on the network, or the amount of competing network trafic.

- Last processed date: The last date on which the complete report process was executed.

- Report file size: This value, expressed in bytes of disk space, serves as a rough indication of the volume of report output that will be generated. The amount shown varies a little trom the file size that would be reported by the DOS directory command, due to differences in the way Paradox and DOS measure space allocation. For non-printing processes, "Unknown" will be displayed.

- The menu shown at the top of the report information screen contains the following selections:

PrtNew Uses the preferred report generation method explained above. All necessary processing is done to extract the current data from the database into a result table. Then, the report is printed or the spreadsheet is generated from that result. The processing time shown on the "Selected Report Information" screen applies to this option.

New Similar to "PrtNew," except that the report goes only to a text file, not to the printer.

Reprint Prints the contents of the result table that was created the last time "PrtNew" or "New" was selected. This is usetul for printing more copies of a report hut will not include database changes made since the last time PrtNew or New was used. The processing time shown on the information screen does not apply here, since no processing is performed by this option.

Store Stores the report in a text file using existing result data. As with "Reprint," updates will not be included and time to process is less than shown on the screen.

Table Returns the user to the report selection screen. Use this to go back and select some other report. 
Quil Ends Report Manager and returns to the SWFD Main Menu.

After a process begins, additional operator input may be required. For example, the user may be asked to choose whether to bypass conversion of volume data from cubic feet to cubic meters. Some report selections also allow the user to accept or bypass the recalculation of PCD volumes. The best choice depends on the circumstances at the time the report is to be run. In all cases, rerunning the optional processes includes current information in the output, but will take extra processing time.

\subsection{Report Manager Output}

By default all reports are sent to printer port LPT1. This default can be changed in the Paradox software setup. See the Paradox User's Guide or ask the database administrator for assistance in changing the report destination.

Spreadsheets are produced in Lotus 1-2-3 Version 2.x format. Each spreadsheet uses the report ID for its name and has ".WK1" as its file name extension. Other spreadsheet types are availahle on request. Spreadsheet files can be found in the ISWPMDB93ISS directory.

Report text files are plain ASCII text files, although most will have a cryptic Hewlett Packard Laserjet printer setup code as the first line in the file. Each file uses the report ID as its name and ".RPT" as the extension. These files are located in the ISWPMDB93IRPT directory. They may be retrieved with WordPerfect or other text and word processor software capable of loading DOS text files. These files may also be printed, as explained in Section 7.3, below.

\subsection{Other Ways to Print Existing Reports}

If you know that the desired report has already been generated, it is not necessary to use Paradox to get a copy of it. The report file can be sent directly to the printer from the DOS prompt. The fiorm of the DOS command is as follows:

\section{COPY J:ISWPMDB93।RPT '"report ID".RPT LPT1}

The "report ID" used as the file name in this command is the same as the identifier for that report displayed on the Report Manager or on report D100. Section 7.2 provides more information about report files. See the database administrator for assistance when needed. The above command assumes that a printer is connected to the LPT1 port. LPT2 or another port could also substituted if necessary. Here is an example of the command to be used to print a report identified as "D106":

COPY J:ISWPMDB93IRPTIDI06.RPT LPT1 
There are other DOS commands besides COPY that will work, such as PRINT and TYPE.

Note: Use the PRINT command with caution, since it will abort a Paradox session where [Alt-O] or [Ctrl-O] were used to get to the DOS prompt. The TYPE command requires the redirection of output to the printer, but allows a suspended Paradox session to resume, as does COPY.

Here are examples of these commands to print the same file used in the COPY example above:

PRINT J:ISWPMDB93|RPTID106.RPT

TYPE J:ISWPMDB93IRPTID106.RPT > PRN 


\section{Appendix}

\section{Versions of Solid Waste Forecast Databases}




\section{APPENDIX - VERSIONS OF SOLID WASTE FORECAST DATABASES}

FY-1989 v1.1

FY-1990 v1.2

FY-1991 v1.3

Reference

FY-1992 v1.4

FY-1993 v1.5

FY-1994 v1.6
Forecast data requested during 1989, covering a forecast period of 1990 through 2020. This database is substantially different in structure than later versions and does not have a fully developed software application for user access. For these reasons, Version 1.1 has been archived on tape and is used only in response to special requests.

Forecast data requested during Fiscal Year 1990, covering a forecast period of 1991 through 2021. This database is in a structure that generally conforms to later versions, but special attention is needed to insure data extracted from it are comparable to the more recent versions. The application software for this version includes provisions for validated data entry and the generation of reference data library files for the model. The database and its application have been archived to tape due to the availability of more current information.

Forecast data requested during Fiscal Year 1991 covering a forecast period of 1992 through 2021. This database does not contain a complete set of forecasts because of nonresponse by a number of waste generatcrs. Its structure supports reasonable comparability with later versions. The application software does not include the ability to produce data for the model, although it has validated data entry capability. This version was archived after the creation of the reference database described below.

This database contains all data available for all waste generators that submitted a Fiscal Year 1991 forecast supplemented by data from Version 1.2 for the non-reporting waste generators. It covers years 1992 through 2021. Its structure is similar enough to other recent versions to support comparative analyses. The application software for this database does not include a data entry feature. A fully functional reference data library generator is available to produce data files for model input.

This database contains forecast data requested during Fiscal Year 1992, covering forecast years 1993 through 2022. Its application software includes complete data entry functionality and an updated reference data library generator to produce model inpul files.

This is the database version addressed by this User's Guide. It contains forecast data requested during Fiscal Year 1993, covering forecast years 1994 through 21)23. Its application software includes complete data entry functionality but does not include the reference data library generator to produce model input files.

At the time of writing of this document, software for this database was under development and data entry had not begun. This database version will contain forecast data requested during Fiscal Year 1994, covering forecast years 1995 through 2024. 


\section{Distribution}

No. of

No. of

Copies

Copies

\section{OFFSITE}

16 Pacific Northwest Laboratory

2 DOE/Office of Scientific and

Technical Information

\section{ONSITE}

DOE Richland Operations Office

L. L. Armacost (5), K8-18

J. A. Jamison, K8-18

M. C. Bierschbach (3), K7-97

G. M. Holter, K7-97

Publishing Coordination

Technical Report Files (5)

R. F. Guercia, R3-80

3 Westinghouse Hanford Company

A. O. Vance, H5-33

O. J. Valero, H5-33

K. L. Hladek, H5-33

Distr.1 

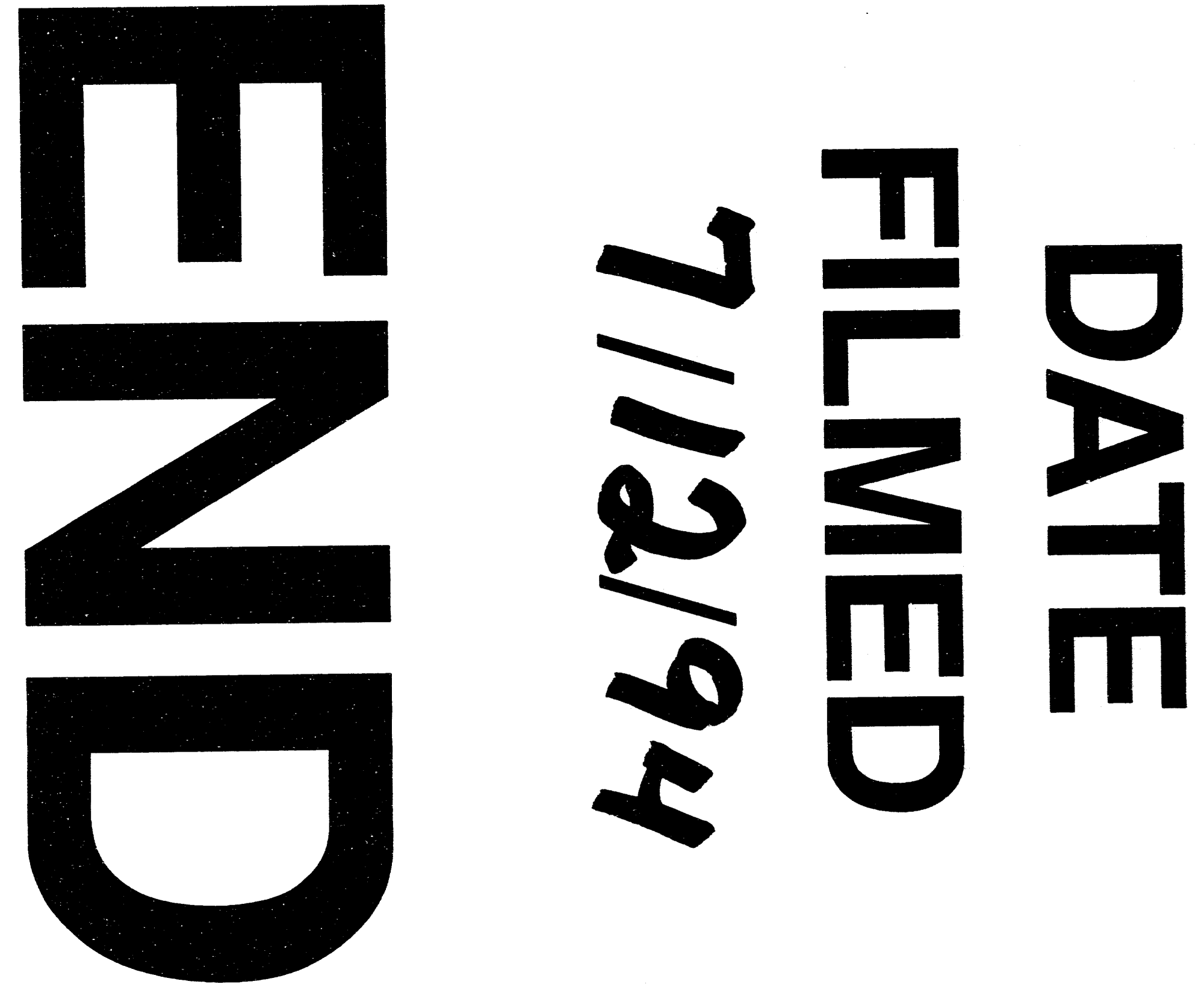

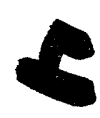


